\title{
Long-term streptozotocin-induced diabetes in rats leads to severe damage of brain blood vessels and neurons via enhanced oxidative stress
}

\author{
HONGYING YANG ${ }^{1}$, SHOURUI FAN ${ }^{1}$, DIANPING SONG ${ }^{2}$, ZHUO WANG ${ }^{1}$, \\ SHUNGAO MA ${ }^{3}$, SHUQING LI ${ }^{4}$, XIAOHONG LI ${ }^{1}$, MIAN XU $^{1}$, MIN XU $^{1}$ and XIANMO WANG ${ }^{1}$ \\ ${ }^{1}$ Department of Clinical Laboratory, The Second Affiliated Hospital of Kunming Medical University; \\ ${ }^{2}$ Department of Diabetes, The First Affiliated Hospital of Kunming Medical University, Kunming 650101; \\ ${ }^{3}$ Department of Pathophysiology, Kunming Medical University, Kunming 650031; \\ ${ }^{4}$ Department of Clinical Laboratory, The First Affiliated Hospital of Dali Medical College, Dali 671000, P.R. China
}

Received August 16, 2012; Accepted November 15, 2012

DOI: $10.3892 / \mathrm{mmr} .2012 .1227$

\begin{abstract}
The aim of this study was to investigate pathophysiological alterations and oxidative stress in various stages of streptozotocin (STZ)-induced diabetes mellitus (DM) in rats. Male Sprague-Dawley rats (120) were randomized into DM and control groups. Body mass, plasma glucose, glycated hemoglobin (HbA1c), superoxide dismutase (SOD), catalase (CAT) and glutathione peroxidase (GPx) levels, as well as aldose reductase (AR) activities, in brain tissue and serum were determined. Electron microscopy was used to observe neuron and vessel changes in the brain. In STZ-treated rats, blood glucose, low density lipoproteins, triglycerides and total cholesterol levels increased 1.43-3.0-fold and high density lipoprotein, HbA1c and insulin sensitivity index increased 1.1-1.23-fold compared with control. At week 16 following treatment, DM rat serum $\mathrm{H}_{2} \mathrm{O}_{2}$ concentration was increased, indicating oxidative stress and mRNA levels of GPx and SOD were 2-fold higher than the control. Protein GPx and SOD levels were reduced $(\mathrm{P}<0.01)$. DM rats were identified to exhibit early irregular glomerular capillary basement membrane thickening and vacuolization in the mitochondria and epithelial cells. Neuron cells and blood vessels in the DM rat brains became increasingly abnormal over time with altered Golgi bodies, mitochondria and endoplasmic reticulum cisterns, concurrent with SOD inactivation and AR protein accumulation. Disease progression in rats with STZ-induced $\mathrm{DM}$ included brain pathologies with vascular and neuron cell
\end{abstract}

Correspondence to: Professor Hongying Yang, Department of Clinical Laboratory, The Second Affiliated Hospital of Kunming Medical University, 374 Dianmian Road, Kunming 650101, P.R. China

E-mail: hongyingyangbm@163.com

Key words: aldose reductase activities, brain neuron cells, diabetic rats, oxidative stress, pathophysiological changes, streptozotocin abnormalities, associated with the reduction of SOD, CAT and GPx activities and also AR accumulation.

\section{Introduction}

Diabetes mellitus (DM) is a disease characterized by a marked increase in blood glucose (BG) and concomitant presence of glucose in urine. Previously, induction of insulin-dependent $\mathrm{DM}$ was confirmed by a marked increase in BG concentration observed in rats following intraperitoneal injection of alloxan monohydrate (1). The principle defect in type 2 (T2) DM is insulin resistance, leading to a relative insulin deficiency in the liver and peripheral tissues with overt hyperglycemia (2). In type 1 (T1) DM, insulin production of the pancreatic Langerhans islet cells is completely eliminated due to a decease in islet cell number. In T1 and 2 DM, glucose uptake is disturbed, particularly in muscle and fat cells, resulting in hyperglycemia. Neuron cells take up glucose without insulin, therefore, in hyperglycemic DM, hyperglycemia causes an up to 4-fold increase in neuronal glucose uptake. Elevated intracellular glucose metabolism leads to neuronal damage (3). In human and animal models, DM was demonstrated to be associated with pathological changes in the central nervous system leading to cognitive and affective deficits and an increased risk of vascular complications in the brain (2). Several brain alterations have been described, including increased hippocampal astrocytic reactivity, impaired synaptic plasticity, vascular alterations, decreased dendritic complexity and disturbed neurotransmission (4). During these pathological changes, damaged mitochondria develop imperfectly coupled electron transport systems, becoming a principal source of reactive oxygen species (ROS) in the cell. Therefore, oxidative stress is widely accepted as a key mediatory process in the development and progression of diabetic complications, due to increased production of free radicals and impaired antioxidant defenses (5). Oxidative stress is also a hallmark of pathophysiological responses resulting from alterations in cellular redox homeostases due to an overproduction of ROS or a deficiency in the buffering or scavenging systems for ROS (6). Antioxidants 
have been classified according to their mode of action and Bonnefont-Rousselot et al (7) differentiated these molecules into three groups: i) antioxidants that prevent the formation of ROS, including ceruloplasmin, metallothioniene, albumin, myoglobin, ferritin and transferrin; ii) scavenging antioxidants which remove ROS once formed, preventing radical chain reactions, including reduced glutathione (GSH), vitamins $\mathrm{E}$ and $\mathrm{C}, \alpha$-carotene, uric acid and billirubin; and iii) enzyme antioxidants that function by catalyzing the oxidation of other molecules, including superoxide dismutase (SOD) which converts superoxide radicals into hydrogen peroxide as well as GSH-peroxidase (GPx) and catalase (CAT) which decompose hydrogen peroxide.

In addition, aldose reductase (AR) is key enzyme in $\mathrm{DM}$ that catalyzes the formation of nicotinamide adenine dinucleotide phospate (NADPH) via the polyol pathway, eventually leading to reduction of glucose to sorbitol (8). AR activity induces diabetic nephropathy by several mechanisms, including increased lipid peroxidation, depletion of major non-enzymatic antioxidants and downregulation of SOD activity (9). The polyol pathway, which is activated by hyperglycemic conditions, may increase the production of superoxide- and NAD-induced ROS and sorbitol levels in tissues may affect myo-inositol content, $\mathrm{Na}^{+}$and $\mathrm{K}^{+}$-ATPase activity and oxidative stress (10). In addition, T2 DM has been associated with an increased risk of developing premature atherosclerosis due to increased triglyceride (TG) and low-density lipoprotein (LDL) levels and decreased high-density lipoprotein (HDL) levels. Therefore, investigating the association between $\mathrm{BG}$, antioxidant enzymes and AR activity in the diabetic brain at various stages following chemically-induced hyperglycemia is important and animal DM models are useful tools to gain new insights into the human form of this disease. Chemicals, including streptozotocin (STZ), a powerful alkylating agent, interfere with glucose transporters and glucokinase function and induce double-strand DNA breaks. To determine the successful establishment in a DM animal model, fasting BG and glucose tolerance tests must be conducted (11). Animals that present with hyperglycemia, uric acid and insulin resistance are classified as successful models of DM. Although the brain is not a classical target organ of insulin, insulin was previously identified as important in human neurophysiology and dysregulation of insulin receptor signaling has been associated with a number of mental illnesses (12). Therefore, the aim of the current study was to evaluate the effects of STZ-induced DM on oxidative stress in the hippocampus, prefrontal cortex and vessels and analyze ionoregulatory disruptions, acute anemia, hyperlipidemia, nephropathy and hepatopathy in an animal model of DM (13).

\section{Materials and methods}

Animals and drugs. Eight-week-old male Sprague-Dawley rats, weighing 170-190 g, were purchased from Vital River Laboratory Animal Technology Co., Ltd. (Beijing, China) and housed in individual cages at a constant temperature $\left(18-22^{\circ} \mathrm{C}\right)$ under a 12-h light-dark cycle. All rats were habituated to the cage for at least 1 week prior to the experiments and randomly divided into 2 groups. The control group was composed of 30 rats. Another group of 90 rats were administered a high-fat and high-sugar diet for 4 weeks (food composition: $32 \%$ carbohydrate, $28 \%$ fat, $17 \%$ protein and $23 \%$ other) to induce insulin resistance (Table I). Following this, $25 \mathrm{mg} / \mathrm{kg}$ STZ dissolved in CASC buffer (Sigma-Aldrich, St. Louis, MO, USA) was injected intraperitoneally. An additional injection $(40 \mathrm{mg} / \mathrm{kg})$ was administered 4 weeks later $(14,15)$ to each rat of the second group. To determine successful establishment of the DM model, BG levels were measured weekly using BG test strips (HMD BioMedical Co., Taiwan, China). The success rate of T2 DM model establishment was 76\%. STZ-injected animals were continuously fed a high-fat and high-sugar diet and the animals were sacrificed at corresponding times $(8,12$ and 16 weeks following model establishment). Brain tissues from the hippocampal region were rapidly removed into ice cold artificial cerebrospinal fluid and glycated hemoglobin (HbA1c) and cholesterol levels were measured (Olympus 5421, Olympus Corporation, Tokyo, Japan) prior to freezing at $-80^{\circ} \mathrm{C}$ for analysis.

The investigation conformed to the Guide for the Care and Use of Laboratory Animals published by the US National Institutes of Health (NIH publication no. 85-23, revised in 1996). Animal experiments followed the ethical standards approved by the Research Ethics Committee of Kunming Medical University (Yunnan, China). The study was approved by the ethics committee of the No. 2 Affiliated Hospital of Kunming Medical University, Kunming, China. Written informed consent was obtained from the patient.

$B G$ and serum insulin estimations. Blood samples were obtained by repeated needle puncture of the tail tip veins 1 day prior to STZ-treatment and every day following DM induction. BG concentrations were determined using Bayer Glucometer Elite ${ }^{\circledR}$ and compatible BG test strips (Bayer, Pittsburgh, PA, USA). Fasted STZ-treated rats with BG concentrations $\geq 16 \mathrm{mmol} / 1$ were considered to have DM and were used in the current study $(16,17)$. Serum insulin concentrations were determined by an enzyme-linked immunosorbent assay, using a commercial kit (Crystal Chem, Chicago, IL, USA).

CAT activity. The activity of CAT was measured using its perioxidase function according to the method of Johansson and Borg (18). Potassium phosphate buffer $(50 \mu \mathrm{l} ; 250 \mathrm{mM}$, $\mathrm{pH}$ 7.0) was incubated with $50 \mu \mathrm{l}$ methanol and $10 \mu \mathrm{l}$ hydrogen peroxide $(0.27 \%)$. The reaction was initiated by the addition of $100 \mu \mathrm{l}$ enzyme sample with continuous agitation at room temperature $\left(25 \pm 1^{\circ} \mathrm{C}\right)$. Following $20 \mathrm{~min}$, the reaction was terminated by addition of $50 \mu 17.8 \mathrm{M}$ potassium hydroxide and $100 \mu \mathrm{l}$ purpald (4-amino-3-hydrazino-5-mercapto-1,2,4-triazole; $34.2 \mathrm{mM}$ in $480 \mathrm{mM} \mathrm{HCl}$ ) was immediately added and the mixture was again incubated for $10 \mathrm{~min}$ at $25 \pm 1^{\circ} \mathrm{C}$ with continuous agitation. Potassium peroxidate $(50 \mu \mathrm{l}$ $65.2 \mathrm{mM}$ solution) was added to obtain a colored compound and the absorbance was read at $550 \mathrm{~nm}$ using a spectrophotometer. Results are expressed as formaldehyde produced $(\mu \mathrm{mol}) /$ protein $(\mathrm{mg})$.

SOD activity. Peripheral blood and brain tissue SOD activity was assayed by the method of Kakkar et al (19). The reac- 
Table I. Nutritional content (\%) of high-fat and ordinary diets.

\begin{tabular}{|c|c|c|c|c|}
\hline \multirow[b]{2}{*}{ Food composition } & \multicolumn{2}{|c|}{ Ordinary diet } & \multicolumn{2}{|c|}{ High-fat and high-sugar diet } \\
\hline & Rate (wt/wt) \% & Total energy $(\%)$ & Rate (wt/wt) $\%$ & Total energy $(\%)$ \\
\hline Carbohydrates & 50 & 62 & 32 & 28 \\
\hline Fat & 5 & 12 & 28 & 57 \\
\hline Protein & 23 & 26 & 17 & 15 \\
\hline Others & 22 & - & 23 & - \\
\hline
\end{tabular}

wt, weight.

tion mixture contained $1.2 \mathrm{ml}$ sodium pyrophosphate buffer (0.052 mM, pH 7.0), $0.1 \mathrm{ml}$ phenazine methosulphate $(186 \mu \mathrm{M})$ and $0.3 \mathrm{ml}$ nitro blue tetrazolium $(300 \mu \mathrm{M})$. Supernatant $(0.2 \mathrm{ml})$ obtained following centrifugation $(1,500 \mathrm{x} \mathrm{g}, 10 \mathrm{~min}$ followed by $10,000 \mathrm{x} \mathrm{g}, 15 \mathrm{~min}$ ) of $5 \%$ tissue homogenate was added to the reaction mixture. The enzyme reaction was initiated by adding $0.2 \mathrm{ml} \mathrm{NADH}(780 \mu \mathrm{M})$ and stopped at $1 \mathrm{~min}$ by adding $1 \mathrm{ml}$ glacial acetic acid. The amount of chromogen formed was measured by recording the color intensity at $560 \mathrm{~nm}$. Results are expressed as U/protein (mg).

GPx activity. GPx activity was measured by NADPH oxidation, using a coupled reaction system consisting of GSH, GSH reductase and cumene hydroperoxide (20). Enzyme sample (100 $\mu \mathrm{l}$ ) was incubated for $5 \mathrm{~min}$ with $1.55 \mathrm{ml}$ stock solution (prepared in $50 \mathrm{mM}$ Tris buffer, $\mathrm{pH} 7.6$ with $0.1 \mathrm{mM}$ EDTA) containing $0.25 \mathrm{mM}$ GSH, $0.12 \mathrm{mM}$ NADPH and 1 unit GSH reductase. The reaction was initiated by adding $50 \mu \mathrm{l}$ cumene hydroperoxide $(1 \mathrm{mg} / \mathrm{ml})$ and the rate of NADPH reduction was determined by monitoring the absorbance at $340 \mathrm{~nm}$. One unit of enzyme activity is defined as the amount of enzyme that transforms $1 \mu \mathrm{mol} \mathrm{NADPH}$ to NADP/min. Results are expressed as $\mathrm{U} /$ protein $(\mathrm{mg})$.

Determination of serum cholesterol, lipoproteins and TG. Blood samples were collected from tail tip veins of rats following $16 \mathrm{~h}$ fasting and transferred to sterilized centrifuge tubes at room temperature. Blood samples were centrifuged for $10 \mathrm{~min}$ at 4,000 $\mathrm{x} \mathrm{g}$ to obtain the serum. Serum was stored in a freezer for later analysis of total cholesterol (TC), TG and HDL- and LDL-cholesterols. Aliquots of serum were obtained for the determination of TC using a enzymatic colorimetric assay method (21) and TG using an enzymatic glycerol phosphate oxidase/peroxidase method described by Cheng et al (22) using an autoanalyzer (Oympus 5421, Olympus Corporation) and ELITech kit. Serum HDL-cholesterol was assayed by precipitation of chylomicrons, while very LDL and LDL were determined with sodium phosphotungstic acid and magnesium chloride (23). Centrifugation was performed to leave only HDL in the supernatant and cholesterol content was determined as described previously (24). Estimation of LDL-cholesterol was performed using the empirical formula reported by Friedewald et al (25) for samples with TG levels $<4.5 \mathrm{mmol} / \mathrm{l}$ : LDL-cholesterol = TC - HDL-cholesterol $\mathrm{TG} / 2.2$; where all concentrations are in $\mathrm{mmol} / \mathrm{l}$.
Protein expression measurements by western blot analysis. Membranes were incubated with primary rat antibodies against SOD, CAT (both obtained from Abzoom Biolabs, Inc., Dallas, TX, USA), GPx (R\&D Systems, Minneapolis, MN, USA), $\beta$-actin (ACTB; Abzoom Biolabs, Inc.) for $2 \mathrm{~h}$ at room temperature. Goat anti-rat horseradish peroxidase (HRP)-conjugated antibodies were used as secondary antibodies and visualized using an electrochemiluminescent detection kit. Values are expressed as $\mathrm{Au} /$ protein (mg). ACTB was used as a loading control.

Quantitative real-time polymerase chain reaction (RT-PCR). Genes were validated by the quantitative RT-PCR-based TaqMan Array (Applied Biosystems, Bedford, MA, USA) system, according to the manufacturer's instructions. Relative gene expression data were obtained using the $2^{-\Delta \Delta \mathrm{CT}}$ method described by the manufacturer's instructions. Briefly, $18 \mathrm{~S}$ ribosomal RNA (18S) was selected as a housekeeping (internal control) gene for normalization of the RT-PCR data. The expression of all five target genes (AR, GPx, Cu-Zu-SOD, CAT; primers are listed in Table II) was normalized against $18 \mathrm{~S}$ expression (relative quantification). Cycle threshold values were set in the exponential range of the amplification plots using the 7300 System Sequence Detection software 1.3 (Applied Biosystems).

Histology and immunostaining. Samples were fixed in $10 \%$ formalin, dehydrated in ascending alcohol and embedded in paraffin for histological examination. The $4-\mu \mathrm{m}$ serial cross-sections were stained with hematoxylin and eosin and observed under a light microscope (Olympus Corporation).

Serial sections were incubated in blocking solution, followed by an overnight incubation at $4^{\circ} \mathrm{C}$ with the following primary antibodies: rabbit anti-SOD (Dako, Carpinteria, CA, USA), rat anti-AR or goat anti-ionized calcium-binding adaptor molecule 1 (Iba1; Abcam, Cambridge, MA, USA). SOD and AR immunostaining sections were rinsed and the EnVision $^{\mathrm{TM}}$ HRP-conjugated system (Dako) was used as secondary reagent.

Electronmicroscopic observations. Cerebral cortex tissues of DM rats were excised and subdivided into small samples for transmission electron microscopy (TEM; JEM-1011, JEOL, Tokyo, Japan) analysis. The collected specimens were fixed in $2.5 \%$ glutaraldehyde buffer, cut into small sections 
Table II. Primer sequences for antioxidant enzyme factors.

\begin{tabular}{|c|c|c|}
\hline Target factors & Primers & Length of amplified fragment $(\mathrm{kb})$ \\
\hline AR & $\begin{array}{l}\text { s GCACGTTCCACGACCAGAGC } \\
\text { as GGGAGGAGCAGGATTCGTCC }\end{array}$ & 739 \\
\hline GPx & $\begin{array}{l}\text { s AGTCCACCGTATATGCCTTC } \\
\text { as TCTGAGGGGATTTTTCTGGA }\end{array}$ & 697 \\
\hline $\mathrm{Cu}-\mathrm{Zn}-\mathrm{SOD}$ & $\begin{array}{l}\text { s GCAGAAGGCAAGCGGTGAAC } \\
\text { as TAGCAGGACAGCAGATGAGT }\end{array}$ & 447 \\
\hline$\beta$-actin & $\begin{array}{l}\text { s GACAGCAGAAAACTTTCGTGC } \\
\text { as TCCAGCCACTCAGTCTTGG }\end{array}$ & 275 \\
\hline
\end{tabular}

$\mathrm{AR}$, aldose reductase; GPx, glutathione peroxidase; SOD, superoxide dismutase; s, sense; as, antisense.

Table III. Basic profile of rat DM (week 16 following model establishment) and control groups.

\begin{tabular}{lccc}
\hline Parameters & Control group & DM group & P-value \\
\hline Body weight, g & $384.76 \pm 34.39$ & $286.53 \pm 24.97$ & $<.01$ \\
Blood glucose & $6.53 \pm 1.83$ & $20.06 \pm 4.76$ & $<0.01$ \\
Insulin sensitivity index & $32.31 \pm 11.77$ & $35.39 \pm 30.63$ & $<0.05$ \\
Fast insulin & $32.31 \pm 11.77$ & $35.39 \pm 30.63$ & $<.05$ \\
Glycosylated hemoglobin & $5.98 \pm 1.19$ & $6.71 \pm 1.37$ & $<.05$ \\
High density lipoprotein & $0.73 \pm 0.18$ & $0.75 \pm 0.41$ & $<0.05$ \\
Low density lipoprotein & $0.36 \pm 0.11$ & $1.72 \pm 0.60$ & $<0.01$ \\
Triglyceride & $0.70 \pm 0.29$ & $1.43 \pm 1.07$ & $<0.01$ \\
Total cholesterol & $1.002 \pm 0.20$ & $<0.01$ \\
\hline
\end{tabular}

DM, diabetes mellitus.

$(\sim 3 \times 1 \times 1 \mathrm{~mm})$ and further fixed in the same fixative for 1 day at room temperature. Sections were rinsed several times in $0.1 \mathrm{~mol} / 1$ phosphate buffer $(\mathrm{pH} 7.4)$ for $1 \mathrm{~h}$ at $4^{\circ} \mathrm{C}$ and then rinsed with distilled water, post-fixed in $1 \%$ osmium tetroxide for $1 \mathrm{~h}$ at room temperature, rinsed again with distilled water and dehydrated in a graded concentration of ethanol. For TEM observation, samples were embedded in resin. Ultra-thin $(110 \mathrm{~nm})$ sections were mounted onto a copper grid, stained with $1 \%$ uranyl acetate for $8 \mathrm{~min}$ and $1 \%$ lead citrate for an additional $10 \mathrm{~min}$ and then examined with an accelerating voltage of $80 \mathrm{kV}$.

Statistical analysis. Results are expressed as the mean $\pm \mathrm{SE}$. ANOVA with multiple comparisons using Bonferroni's test or one-way ANOVA was performed where appropriate. GraphPad Prism (v3.02) was used for linear regression, curve fitting and dose-response analysis. $\mathrm{P}<0.05$ was considered to indicate a statistically significant difference.

\section{Results}

Blood analysis of DM patients and rats. DM rats exhibited elevated BG, HDL, LDL, TG, TC and HbA1c levels at week 16 following STZ injection $(\mathrm{P}<0.05, \mathrm{P}<0.01)$, whereas their weights decreased (Table III). Lipid abnormalities of DM rats were compared with data from 185 DM patients from the Second Affiliated Hospital of Kunming Medical University treated between April and May 2008 and Febuary and March 2009 (Table IV). The comparison indicated that the high-fat and -glucose diet following 2 STZ injections in rats reflects the incidence of dyslipidemia in T2 DM patients.

Oxidative stress and antioxidant enzyme changes in the STZ-induced DM rat group. At week 16 following STD induction, $\mathrm{O}_{2}$ and $\mathrm{H}_{2} \mathrm{O}_{2}$ serum levels of DM and control rats were determined. As demonstrated in Fig. 1A, levels were significantly enhanced in the STZ-treated group. Fig. 1B reveals that GPx protein levels in the brain tissues 8 weeks following STZ-induction were enhanced in DM rats, compared with the control. By contrast, CAT protein levels were decreased in the brains of the DM group compared with the control at 8 weeks. At week 16 following STZ-induction GPx and CAT protein levels in the brain tissues were substantially lower in the DM group than the control. Fig. $1 \mathrm{C}$ presents GPx and $\mathrm{Cu}-\mathrm{Zn}-\mathrm{SOD}$ mRNA levels in the blood serum of DM and control rats at week 16 following STZ-induction, indicating that the transcription of GPx and $\mathrm{Cu}-\mathrm{Zn}-\mathrm{SOD}$ was enhanced in DM rats. By contrast, GPx and SOD protein levels were reduced in the 
Table IV. Comparison of lipid abnormalities cases between DM patients and rats.

\begin{tabular}{lccr}
\hline Cases & DM patients (type 2) & DM rats (type 2) & P-value \\
\hline Total number & $185(100)$ & $30(100)$ & $>0.05$ \\
Lipid abnormal & $51(34.33)$ & $14(47.21)$ & $>0.05$ \\
HDL reduction & $8(4.44)$ & $1(3.68)$ & $>0.05$ \\
LDL increasing & $31(21.34)$ & $7(23.37)$ & $>0.05$ \\
TC increasing & $21(14.92)$ & $6(20.31)$ & $>0.05$ \\
TG increasing & $29(19.59)$ & $>0.05$ & \\
\hline
\end{tabular}

Numbers in brackets show \%. DM, diabetes mellitus; HDL, high-density lipoprotein; LDL, low-density lipoprotein; TC, total cholesterol; TG, triglyceride.
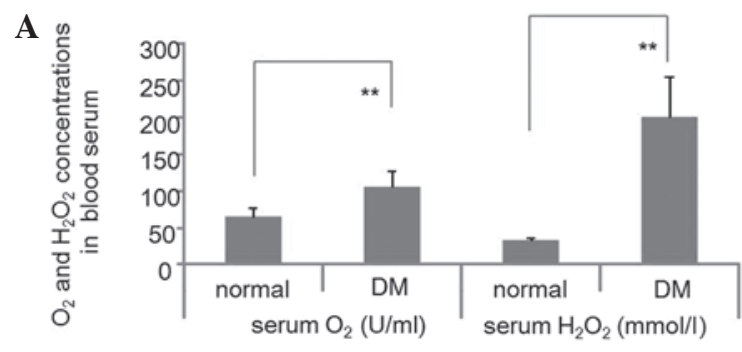

B
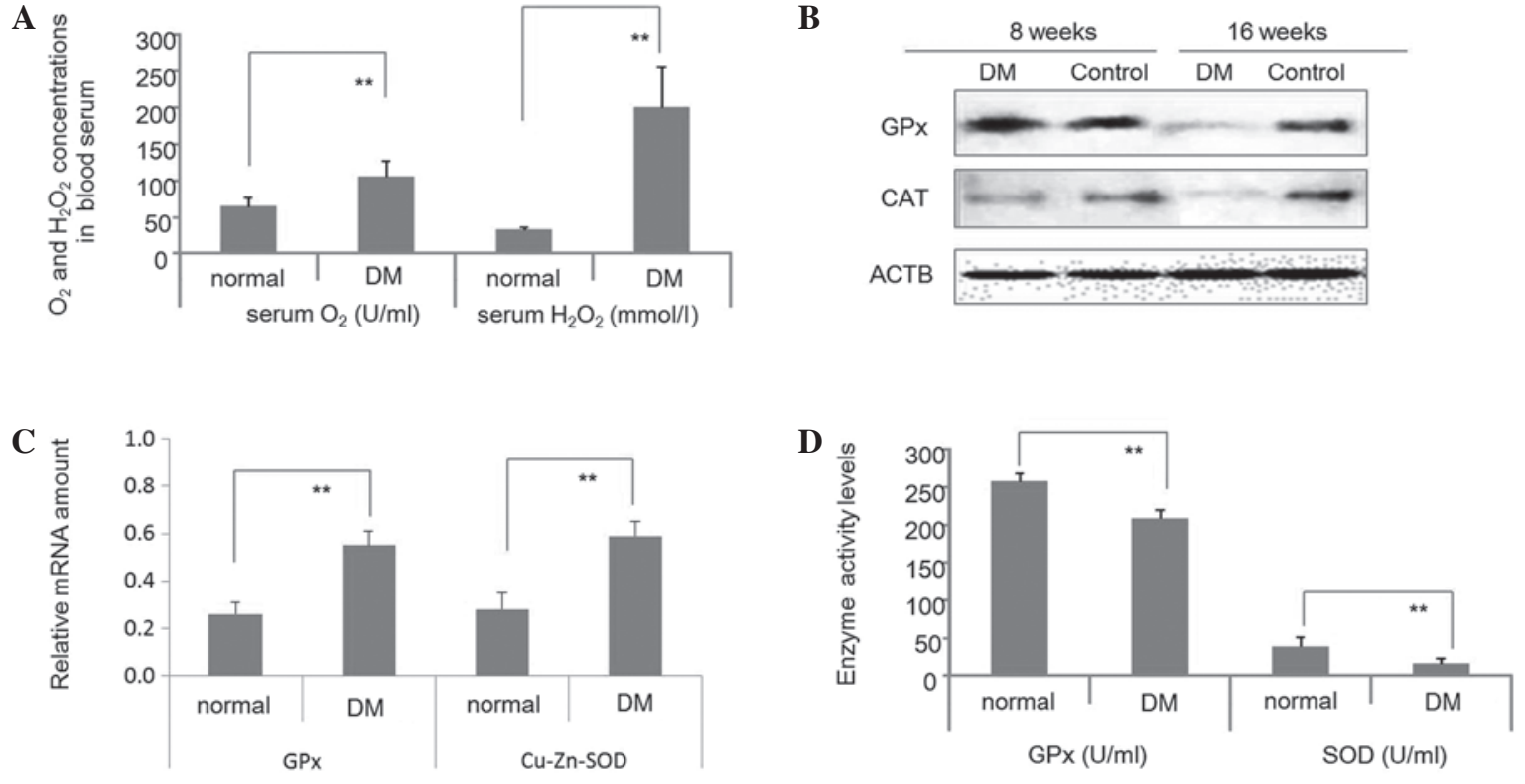

Figure 1. Oxidative stress and antioxidant enzyme changes in the STZ-induced DM rat group. (A) $\mathrm{O}_{2}$ and $\mathrm{H}_{2} \mathrm{O}_{2}$ serum concentration at week 16 following STZ-induction. (B) Western blot analysis of antioxidant enzyme protein levels in brain tissue at weeks 8 and 16 following STZ-induction. (C) Relative serum mRNA levels and (D) protein levels of antioxidant enzymes at week 16 following STZ-induction in DM and control rats. STZ, streptozotocin; GPx, glutathione peroxidase; SOD, superoxide dismutase; CAT, catalase; ACTB, $\beta$-actin. ${ }^{* *} \mathrm{P}<0.01$ compared with the control group.

blood serum of DM rats at week 16 (Fig. 1D). SOD staining in the cortex, hippocampus and blood vessels of DM rat brains revealed that SOD increased in the early stages following STZ-induction (week 8), however, at later stages following DM establishment, levels reduced with the severity of dyslipidemia in brain tissues (week 16; Fig. 2).

AR accumulation in DM rat brains. In STZ-treated DM rats, mRNA levels and enzyme activities of AR significantly increased in blood sera and brains of DM rats at week 16 following STZ-induced DM (Fig. 3; P<0.05). Consistent with these observations, AR immunostaining revealed an accumulation of AR protein at weeks 8 and 16 following STZ-induction in the cortex, hippocampus and vessels of the DM rat brains (Fig. 4).

Varying degrees of pathological changes on cerebral blood vessels and neural tissue with disease progression of DM. To explore the pathological changes in various stages of DM, vessels and neural cells in DM rat brains were analyzed using electron microscopy. Lumen stenosis (Fig. 5B), vessel wall collapse (Fig. 5C), frame loss and endothelial cell swelling and shedding (Fig. 5C) was identified in vessels and vessel thickening and perivascular edema development was revealed to increase with disease severity (Fig. 6). In addition, proliferation of glial cells in the brain at week 8 following DM rat model establishment was observed (Fig. 7). Neuron cells were shrunken and cell membranes became blurry at week 16 following DM onset (Fig. 8). In addition, this damage developed in the mitochondria, Golgi bodies and rough endoplasmic reticulua of neuron cells (Fig. 9), clearly demonstrating that these pathological changes were dependent on the time of disease progression (Fig. 10).

\section{Discussion}

In previous years, 30 genes from the hippocampus, including the inhibitory neuropeptide galanin, synuclein $\gamma$ and uncou- 

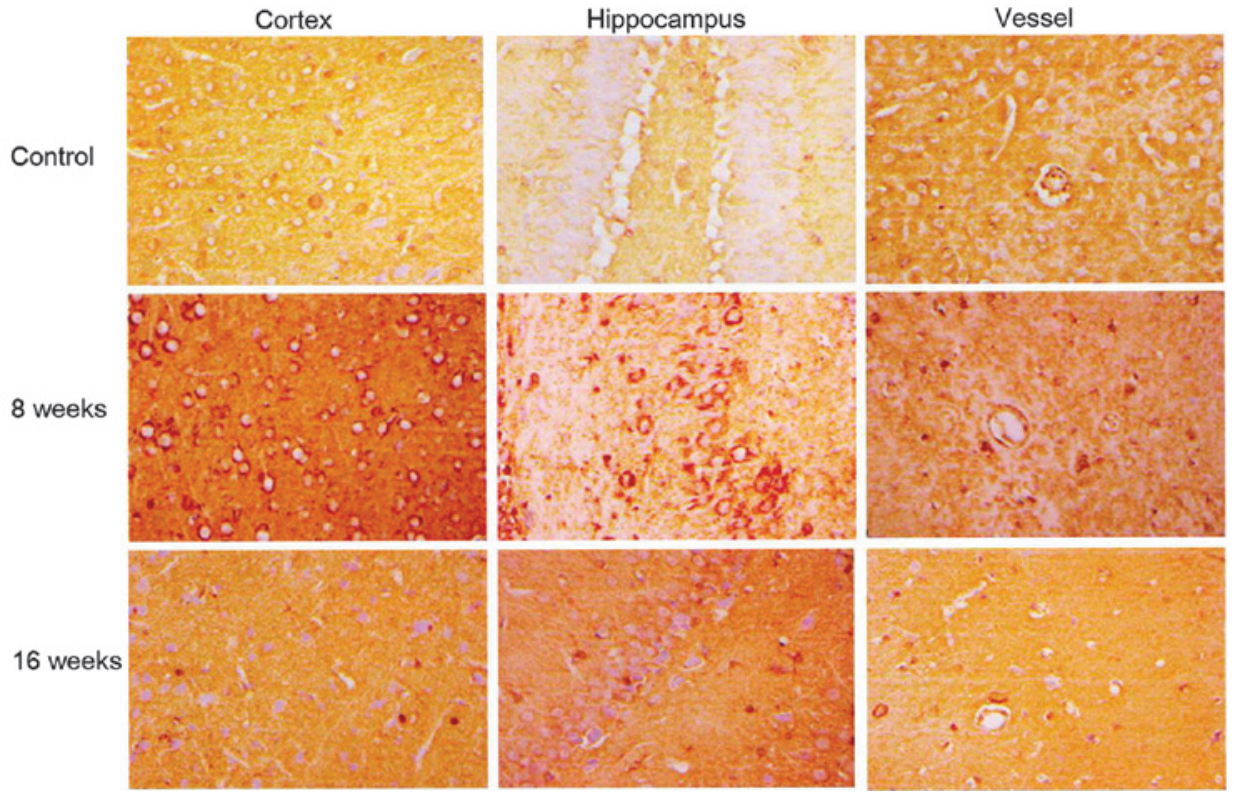

Figure 2. Pathological changes at various stages of DM induced by STZ. Red staining indicates SOD antibody immunostaining in the cortex, hippocampus and vessels of the diabetic and control rats. DM, diabetes mellitus; STZ, streptozotocin; SOD, superoxide dismutase.

A

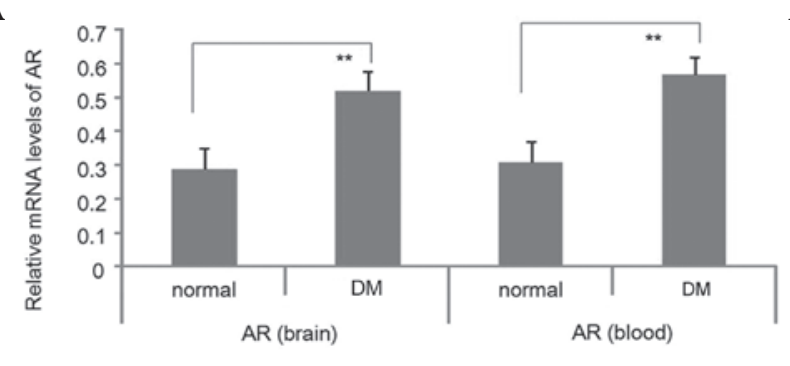

B

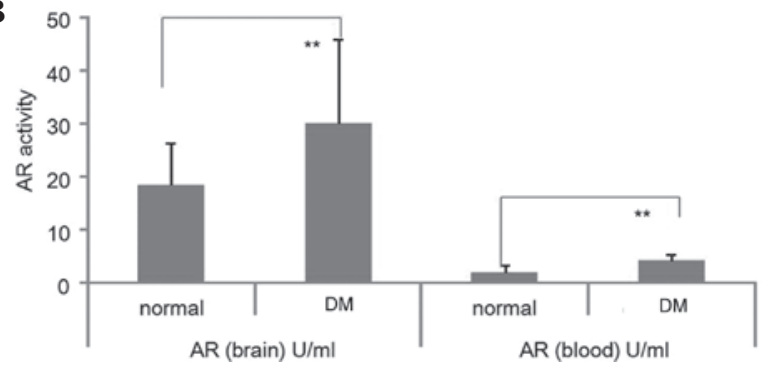

Figure 3. Oxidative stress-induced changes of AR in the blood and brain tissue of DM rats and control rats at week 16 following STZ-induction. (A) Relative mRNA levels and (B) protein activities of AR in brain tissue and blood. STZ, streptozotocin; AR, aldose reductase; DM, diabetes mellitus. ${ }^{* *} \mathrm{P}<0.01$ compared with the control group.
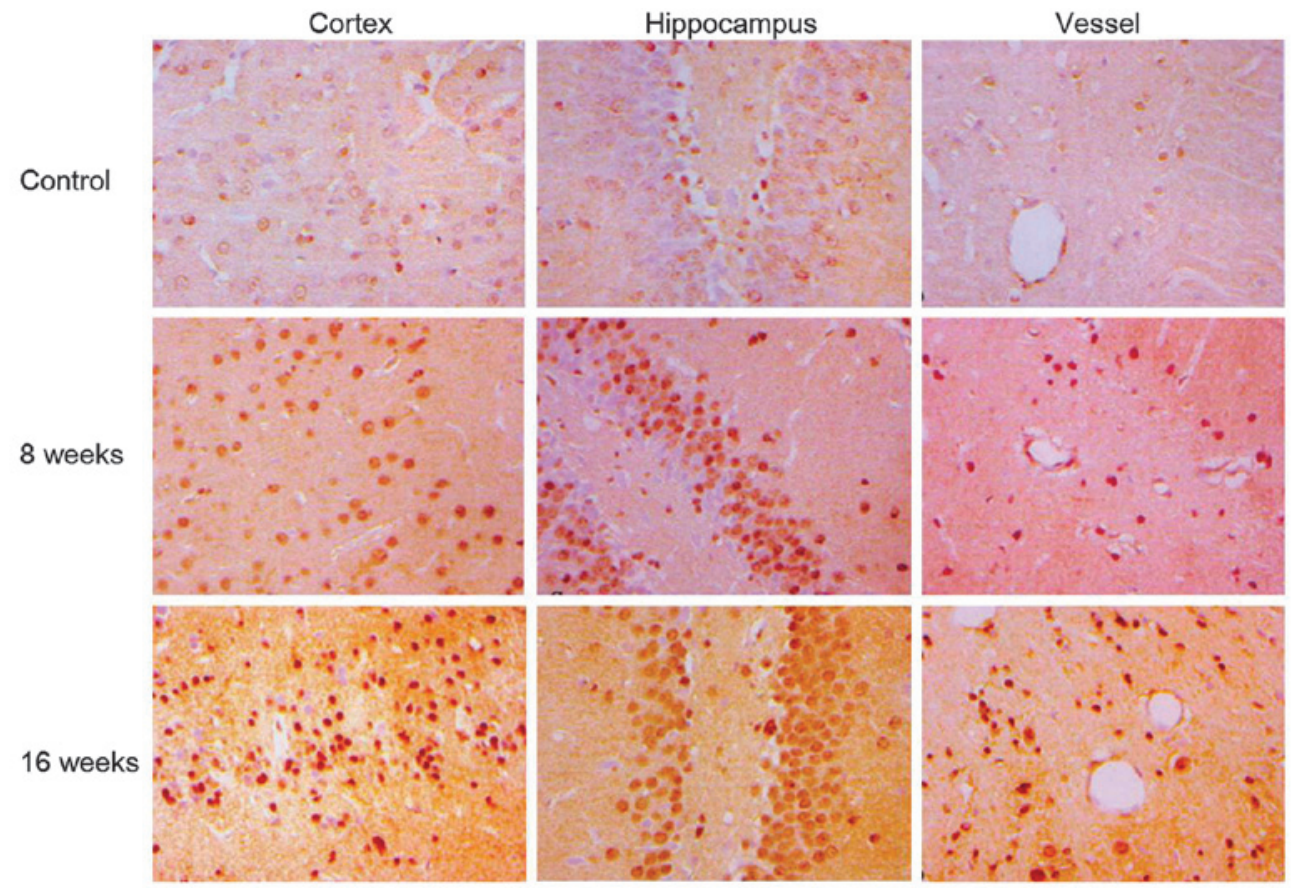

Figure 4. AR accumulation at various stages of DM induced by STZ. Red staining indicates AR antibody immunostaining in the cortex, hippocampus and vessels in diabetic and control rats at the indicated times following DM induction. STZ, streptozotocin; AR, aldose reductase; DM, diabetes mellitus. 

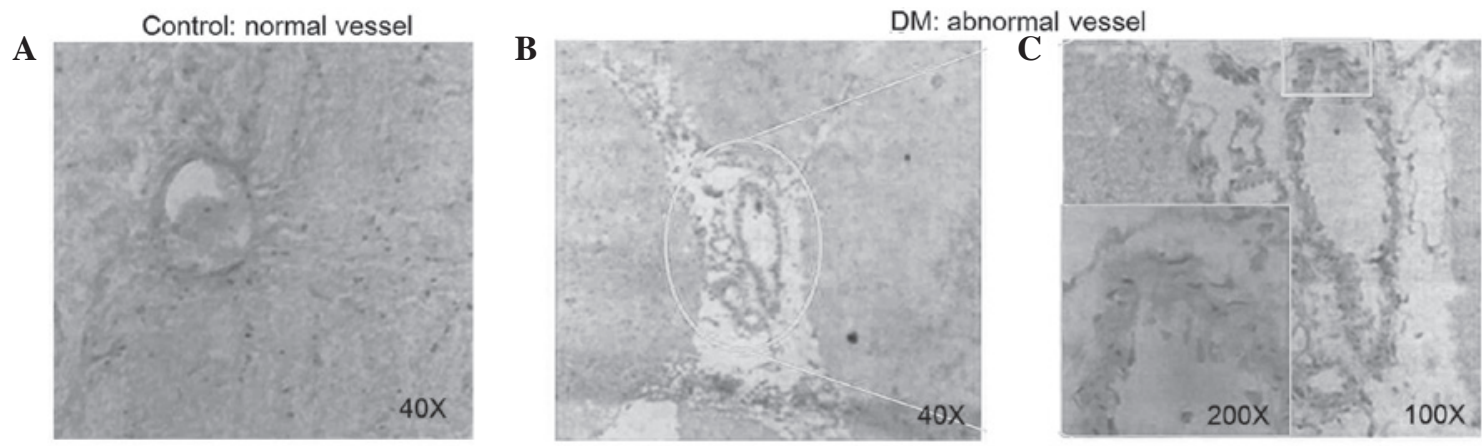

Figure 5. Hematoxylin and eosin vessel staining in (A) control (A) and (B and C) STZ-induced DM rats. Images demonstrate vascular lumen stenosis, wall collapse and frame loss and endothelial cell swelling and shedding in DM rats at week 16 following STZ-induction. STZ, streptozotocin. DM, diabetes mellitus.
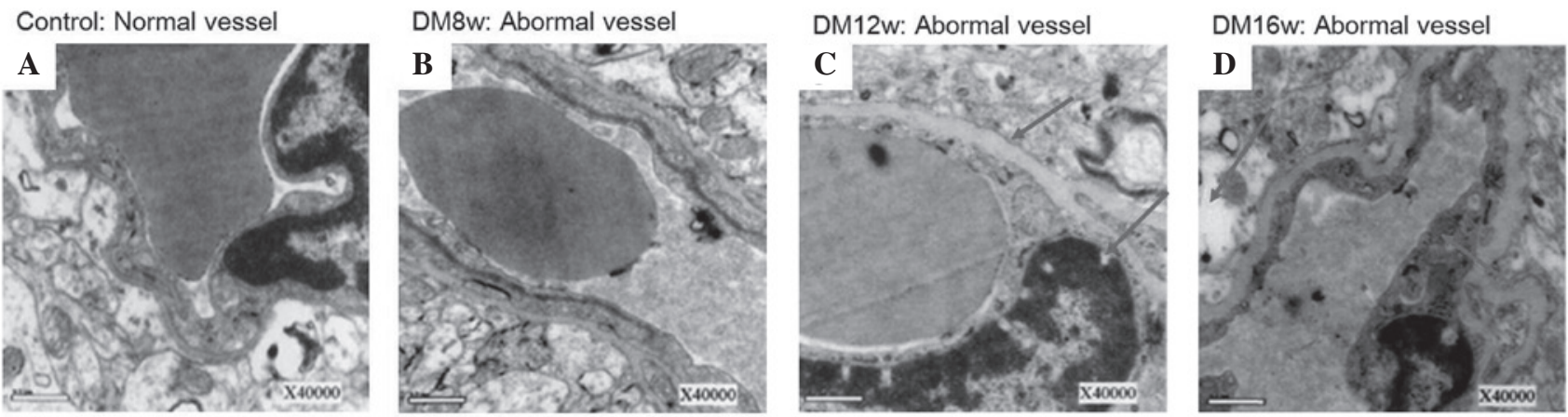

Figure 6. Ultra-microstructure of cerebral cortex tissue from (A) control or DM groups at weeks (B) 8, (C) 12 and (D) 16 following DM induction. Arrows indicate thickened vascular basal membranes, intravascular pool, glutinous platelets at endothelial cell surfaces and perivascular edema. DM, diabetes mellitus.
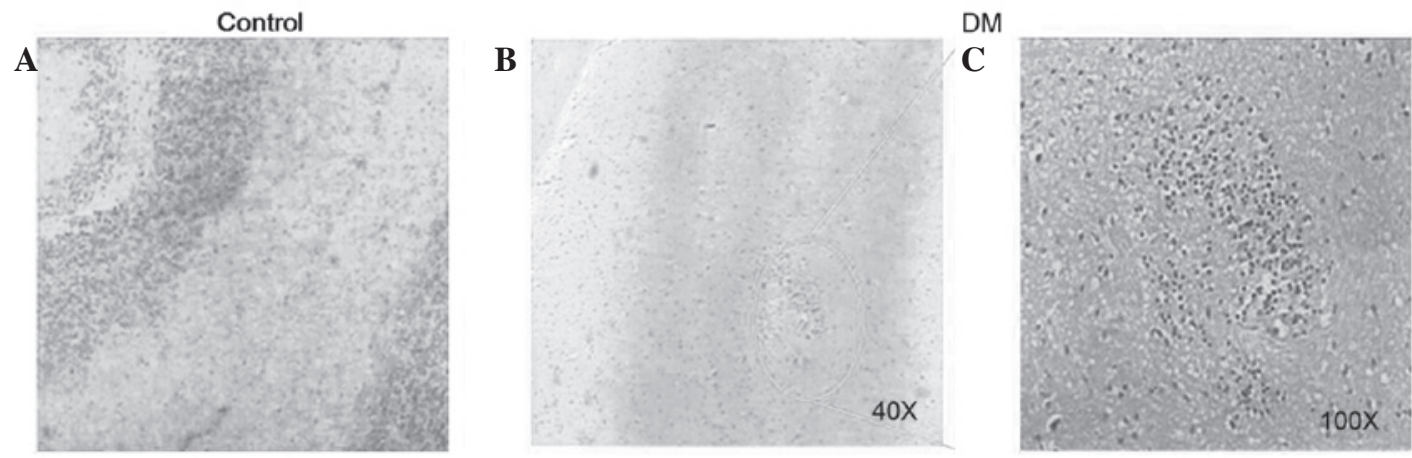

Figure 7. Hematoxylin and eosin staining of glial cells in the brain of (A) control and (B and C) STZ-induced DM rats at week 8. Increased proliferation of glia cells was identified in diabetic rats compared with control. STZ, streptozotocin; DM, diabetes mellitus.
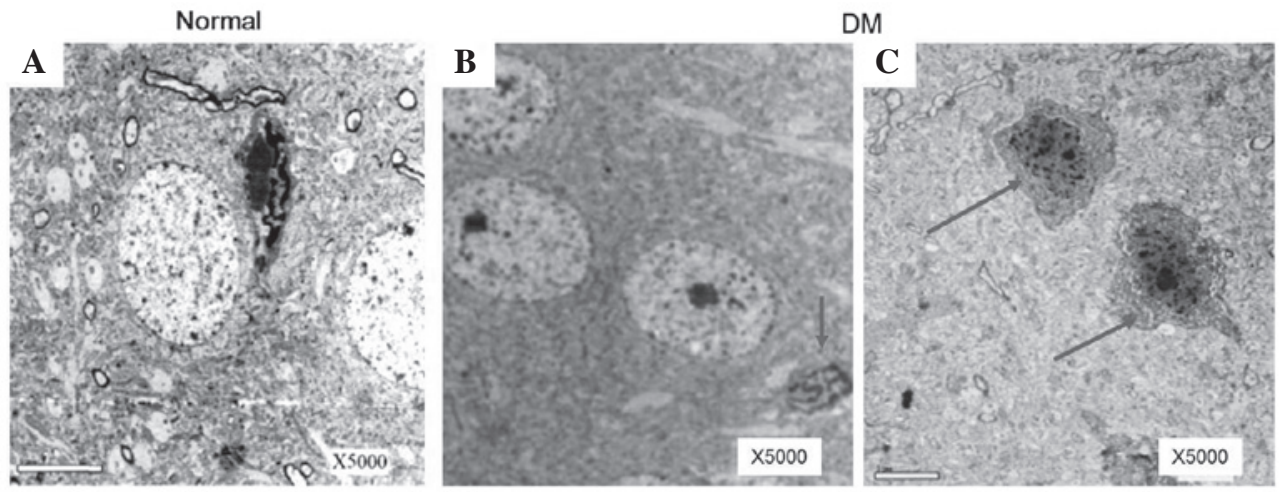

Figure 8. Cerebral cortex tissue ultra-microstructures of (A) control and (B and C) DM groups, demonstrating (B) shrunken neuron cells at week 8 and (C) wizened nuclear membranes and a blurry structure of cellular organs at week 16 . DM, diabetes mellitus. 
Table V. Blood glucose in various stages of control and DM rat group establishment.

\begin{tabular}{lccr}
\hline & \multicolumn{2}{c}{ Blood glucose concentration (mmol/l) } \\
\cline { 2 - 4 } Stage of group establishment & Control group & DM group & t-value \\
\hline High-fat diet for 4 weeks & $6.55 \pm 1.34$ & $6.61 \pm 1.43$ & 1.457 \\
STZ injection 1 & $6.13 \pm 1.43$ & $17.78 \pm 3.69$ & $7.547^{\mathrm{a}}$ \\
Prior to STZ injection 2 & $6.80 \pm 1.32$ & $15.80 \pm 2.76$ & $7.114^{\mathrm{a}}$ \\
Following STZ injection 2 & $6.84 \pm 3.40$ & $18.61 \pm 3.65$ & $10.098^{\mathrm{a}}$ \\
Week 16 following model establishment & $6.53 \pm 1.83$ & $20.06 \pm 4.76$ & $11.849^{\mathrm{a}}$ \\
\hline
\end{tabular}

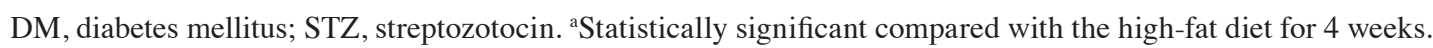
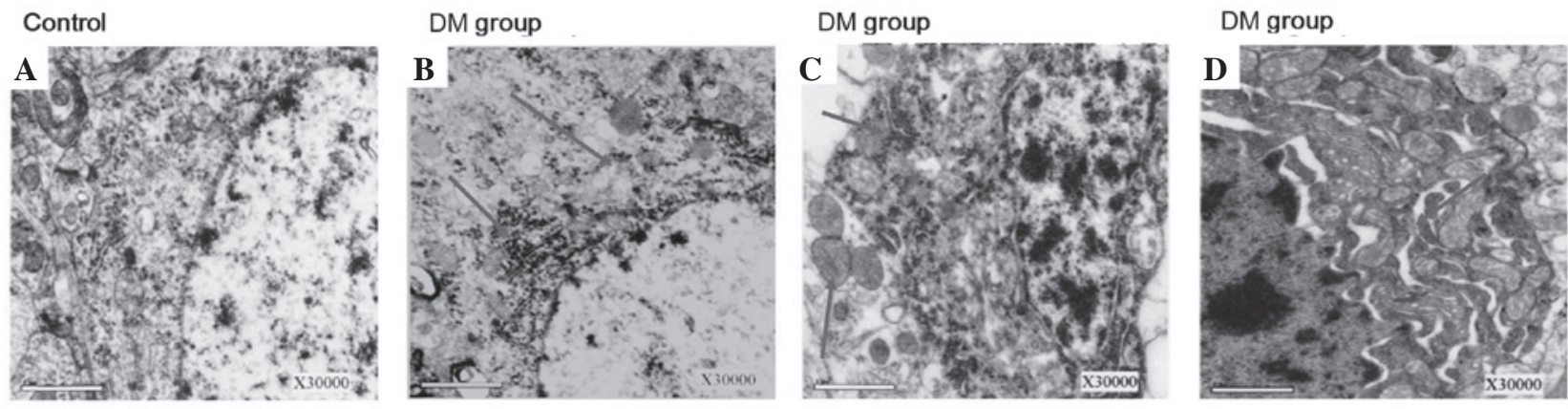

Figure 9. Ultra-microstructure of cerebral cortex tissue revealed condensed nuclei, crimpled cell and nuclear membrane in week 8 (A) control and (B) DM rats. (C) Swollen chondriosomes and hyperplasia of the Golgi body in DM rat. (D) Formation of endoplasmic reticulum cisternae, apposing mitochondria and rough endoplasmic reticulum in DM rat. DM, diabetes mellitus.
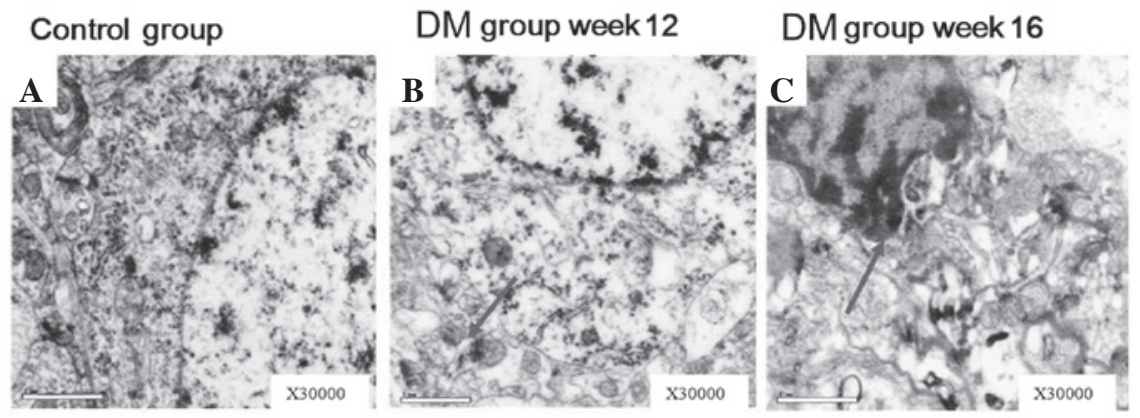

Figure 10. (A) Ultra-microstructure of cerebral cortex tissue demonstrating neuron cells in (A) control and (B) DM group at week 12 in which only a few neurocytes began to shrink, the mitochondria increased in number and pyknosis occured. (C) DM rat at week 16 demonstrating increases in wizened neurocyte and a blurry organ structure of the cells. DM, diabetes mellitus.

pling protein 2 , as well as 22 genes from the prefrontal cortex, including galanin receptor 2, protein kinase $\mathrm{C} \gamma$ and $\varepsilon$, ATP-binding cassette A1, cluster of differentiation 47 and the rearranged during transfection proto-oncogene, were found to exhibit altered expression levels in T2 DM model animals compared with non-DM controls using pathway analysis and validation of genes by RT-PCR. Gene lists were identified to be partly overlapping and included genes associated with neurotransmission, lipid metabolism, neuronal development, insulin secretion, oxidative damage and DNA repair (26). In DM, protein glycation and glucose auto-oxidation leads to formation of free radicals which induce lipid peroxidation (27). Increased lipid peroxidation impairs membrane functions by decreasing membrane fluidity and changing the activity of membrane-bound enzymes and receptors (28) and was observed in the present study (Figs. 8-10). Oxidative stress in DM causes disturbances at the level of subcellular organelles, including mitochondrial damage which, in turn, generates further oxidative stress inside the cell. With hyperglycemia and abnormalities in serum lipids, DM is usually associated with microvascular and macrovascular complications which are the major causes of morbidity and mortality in diabetic individuals (29).

In the present study, elevated serum lipids were observed in STZ-treated DM rats (Tables III and V). Lipids are important for the pathogenesis of DM. Serum lipid levels are usually raised in DM and represent a risk factor for brain disease. A previous study demonstrated that elevated LDL, TG and TC 
and an increase in STZ-induced HDL levels, may be beneficial for the prevention of complications associated with DM, as well as improving lipid metabolism (30). At early stages following STZ injection, damage of brain tissue was limited, despite rapid $\mathrm{BG}$ increase, indicating that $\mathrm{BG}$ was not associated with antioxidant enzyme activities in DM rats during early stages of the disease. Previously, variable antioxidant enzyme responses to DM have been noted in brain tissues, with observations of either unchanged, increased or decreased GSH reductase (31-33). These results indicate that antioxidant enzyme activity varies between tissue types and the severity of DM at various stages may be a major contributing factor.

In the present study, experimental DM was observed to increase SOD and reduce CAT protein levels in brain tissue at week 8 following STZ-induction (Figs. 2 and 1B). Previous studies on the effects of experimental DM on SOD or CAT activities in tissues have been inconsistent (34-37) and are likely to be dependent on several factors, including differential baseline expression of these enzymes and techniques used to generate the DM animals. In addition, oxidative stress is widely accepted as a key mediator in the development and progression of DM and its complications, due to the increased production of free radicals and impaired antioxidant defenses (5). The present findings revealed that SOD and CAT activities decreased in the cortex, hippocampus and vessels at week 16 following DM onset. SOD is a protective enzyme that selectively scavenges the superoxide anion radical $\left(\mathrm{O}_{2}^{-*}\right)$ by catalyzing its dismutation to hydrogen peroxide $\left(\mathrm{H}_{2} \mathrm{O}_{2}\right)$. CAT catalyzes the degradation of $\mathrm{H}_{2} \mathrm{O}_{2}$ to water and $\mathrm{O}_{2}$. An additional study demonstrated that SOD and CAT activities were increased in livers of alloxan-induced DM rats (38). Di Naso et al (39) reported that exogenous antioxidant $\mathrm{Cu}-\mathrm{Zn}$ SOD decreased liver peroxidation and increased nitric oxide synthase in DM rats. Considering the pathophysiology of DM and the results presented in this study, we hypothesize that differences in oxidative stress parameters may be associated, at least in part, with brain metabolism. GPx levels in DM rat brains first increased at week 8 and then markedly decreased at week 16 following STZ-induction (Fig. 1B), consistent with blood serum GPx levels presented in Fig. 1C. All measured oxidative stress quenching enzyme activities (SOD, CAT and GPx) were reduced at week 16, whereas transcription of GPx and $\mathrm{Cu}-\mathrm{Zn}$-SOD were enhanced at this time. Concomitant AR accumulation in the same tissue was present at week 8 (Fig. 4). We hypothesize that in the first 8 weeks following STZ-induction of DM, oxidative stress increases, but is compensated, in part, by maintained levels of GPx (Fig. 1B) and accumulation of SOD (Fig. 2), however CAT levels are already reduced. At the same time AR accumulates in neuron cells (Fig. 4), leading to increased NADPH depletion and reduced GSH production. At week 16, AR expression is enhanced further and $\mathrm{Cu}-\mathrm{Zn}-\mathrm{SOD}$ and GPx transcription and enzymatic activities and CAT levels in the brain tissues are markedly reduced, leading to accumulation of cell damage caused by oxidative stress, which was only partly visible at week 8 of DM onset (Figs. 5-10).

Based on the current study, STZ treatment is associated with oxidative stress in brain tissues. Prolonged DM with a high-fat diet led to AR accumulation and concomitant depletion of GPx, SOD and CAT activities in the neuron cells of rats, leading to pathological changes of cortex, hippocampus and vessel cell structures caused by accumulation of oxidative stress and reduced antioxidant enzyme activity.

\section{Acknowledgements}

The authors thank Dr Mingxing Ma for technical assistance. The present study was supported by grants from the Native Science Institutes of China (81060141), the Foundation Research of Yunnan Province (2007C0013R) and the Special Foundation of Kunming Medical University.

\section{References}

1. Piro S, Anello M, Di Pietro C, et al: Chronic exposure to free fatty acids or high glucose induces apoptosis in rat pancreatic islets: possible role of oxidative stress. Metabolism 51: 1340-1347, 2002.

2. Biessels GJ and Gispen WH: The impact of diabetes on cognition: what can be learned from rodent models? Neurobiol Aging 26 (Suppl 1): 36-41, 2005.

3. Tomlinson DR and Gardiner NJ: Glucose neurotoxicity. Nat Rev Neurosci 9: 36-45, 2008.

4. Magarinos AM and McEwen BS: Experimental diabetes in rats causes hippocampal dendritic and synaptic reorganization and increased glucocorticoid reactivity to stress. Proc Natl Acad Sci USA 97: 11056-11061, 2000.

5. Ceriello A: New insights on oxidative stress and diabetic complications may lead to a 'causal' antioxidant therapy. Diabetes Care 26: 1589-1596, 2003.

6. S Roriz-Filho J, Sá-Roriz TM, Rosset I, et al: (Pre)diabetes, brain aging and cognition. Biochim Biophys Acta 1792: 432-443, 2009.

7. Bonnefont-Rousselot D, Bastard JP, Jaudon MC and Delattre J: Consequences of the diabetic status on the oxidant/antioxidant balance. Diabetes Metab 26: 163-176, 2000.

8. Tang WH, Martin KA and Hwa J: Aldose reductase, oxidative stress, and diabetic mellitus. Front Pharmacol 3: 87, 2012.

9. Obrosova IG, Van Huysen C, Fathallah L, Cao XC, Greene DA and Stevens MJ: An aldose reductase inhibitor reverses early diabetes-induced changes in peripheral nerve function, metabolism and antioxidative defense. FASEB J 16: 123-125, 2002.

10. Oates PJ: Aldose reductase, still a compelling target for diabetic neuropathy. Curr Drug Targets 9: 14-36, 2008.

11. Watala C, Kazmierczak P, Dobaczewski M, et al: Anti-diabetic effects of 1-methylnicotinamide (MNA) in streptozocin-induced diabetes in rats. Pharmacol Rep 61: 86-98, 2009.

12. Huang CC, Lee CC and Hsu KS: The role of insulin receptor signaling in synaptic plasticity and cognitive function. Chang Gung Med J 33: 115-125, 2010.

13. Adeyi AO, Idowu BA, Mafiana CF, Oluwalana SA, Ajayi OL and Akinloye OA: Rat model of food-induced non-obese-type 2 diabetes mellitus: comparative pathophysiology and histopathology. Int J Physiol Pathophysiol Pharmacol 4: 51-58, 2012.

14. Islam MS and Choi H: Nongenetic model of type 2 diabetes: a comparative study. Pharmacology 79: 243-249, 2007.

15. Zhang L, Zhang Y, Xia Q, et al: Effective control of blood glucose status and toxicity in streptozotocin-induced diabetic rats by orally administration of vanadate in an herbal decoction. Food Chem Toxicol 46: 2996-3002, 2008.

16. Chavez M, Seeley RJ, Havel PJ, Friedman MI, Matson CA, Woods SC and Schwartz MW: Effect of a high-fat diet on food intake and hypothalamic neuropeptide gene expression in streptozotocin diabetes. J Clin Invest 102: 340-346, 1998.

17. Schaue D, Jahns J, Hildebrandt G and Trott KR: Radiation treatment of acute inflammation in mice. Int J Radiat Biol 81: 657-667, 2005

18. Johansson LH and Borg LA: A spectrophotometric method for determination of catalase activity in small tissue samples. Anal Biochem 174: 331-336, 1988.

19. Kakkar P, Das B and Viswanathan PN: A modified spectrophotometric assay of superoxide dismutase. Indian J Biochem Biophys 21: 130-132, 1984

20. Tappel AL: Glutathione peroxidase and hydroperoxides. Methods Enzymol 52: 506-513, 1978. 
21. Allain CC, Poon LS, Chan CS, Richmond W and Fu PC: Enzymatic determination of total serum cholesterol. Clin Chem 20: 470-475, 1974.

22. Cheng ML, Kammerer CM, Lowe WF, Dyke B and VandeBerg JL: Method for quantitating cholesterol in subfractions of serum lipoproteins separated by gradient gel electrophoresis. Biochem Genet 26: 657-681, 1988 .

23. Rainwater DL, Ludwig MJ, Haffner SM and VandeBerg JL: Lipid and lipoprotein factors associated with variation in Lp(a) density. Arterioscler Thromb Vasc Biol 15: 313-319, 1995.

24. Lopes-Virella MF, Stone P, Ellis S and Colwell JA: Cholesterol determination in high-density lipoproteins separated by three different methods. Clin Chem 23: 882-884, 1977.

25. Friedewald WT, Levy RI and Fredrickson DS: Estimation of the concentration of low-density lipoprotein cholesterol in plasma, without use of the preparative ultracentrifuge. Clin Chem 18: 499-502, 1972

26. Abdul-Rahman O, Sasvari-Szekely M, Ver A, Rosta K, Szasz BK, Kereszturi E and Keszler G: Altered gene expression profiles in the hippocampus and prefrontal cortex of type 2 diabetic rats. BMC Genomics 13: 81, 2012.

27. Baynes JW: Role of oxidative stress in development of complications in diabetes. Diabetes 40: 405-412, 1991.

28. Baynes RD: Transferrin reduces the production of soluble transferrin receptor. Proc Soc Exp Biol Med 209: 286-294 1995.

29. Furukawa S, Fujita T, Shimabukuro M, et al: Increased oxidative stress in obesity and its impact on metabolic syndrome. J Clin Invest 114: 1752-1761, 2004.

30. Adewole SO and Ojewole JA: Protective effects of Annona muricata Linn. (Annonaceae) leaf aqueous extract on serum lipid profiles and oxidative stress in hepatocytes of streptozotocin-treated diabetic rats. Afr J Tradit Complement Altern Med 6: 30-41, 2008

31. Kamalakkannan N and Stanely Mainzen Prince P: Rutin improves the antioxidant status in streptozotocin-induced diabetic rat tissues. Mol Cell Biochem 293: 211-219, 2006.
32. Nazaroglu NK, Sepici-Dincel A and Altan N: The effects of sulfonylurea glyburide on superoxide dismutase, catalase and glutathione peroxidase activities in the brain tissue of streptozotocin-induced diabetic rat. J Diabetes Complications 23: 209-213, 2009

33. Ulusu NN, Sahilli M, Avci A, et al: Pentose phosphate pathway, glutathione-dependent enzymes and antioxidant defense during oxidative stress in diabetic rodent brain and peripheral organs: effects of stobadine and vitamin E. Neurochem Res 28: 815-823, 2003.

34. Huang WC, Juang SW, Liu IM, Chi TC and Cheng JT: Changes of superoxide dismutase gene expression and activity in the brain of streptozotocin-induced diabetic rats. Neurosci Lett 275: 25-28, 1999.

35. Hunkar T, Aktan F, Ceylan A and Karasu C: Effects of cod liver oil on tissue antioxidant pathways in normal and streptozotocin-diabetic rats. Cell Biochem Funct 20: 297-302, 2002.

36. Ozkaya YG, Agar A, Yargicoglu P, Hacioglu G, Bilmen-Sarikcioglu S, Ozen I and Alicigüzel Y: The effect of exercise on brain antioxidant status of diabetic rats. Diabetes Metab 28: 377-384, 2002.

37. Sechi LA, Ceriello A, Griffin CA, Catena C, Amstad P, Schambelan $\mathrm{M}$ and Bartoli E: Renal antioxidant enzyme mRNA levels are increased in rats with experimental diabetes mellitus. Diabetologia 40: 23-29, 1997.

38. Bree AJ, Puente EC, Daphna-Iken D and Fisher SJ: Diabetes increases brain damage caused by severe hypoglycemia. Am J Physiol Endocrinol Metab 297: E194-E201, 2009.

39. Di Naso FC, Simoes Dias A, Porawski M and Marroni NA: Exogenous superoxide dismutase: action on liver oxidative stress in animals with streptozotocin-induced diabetes. Exp Diabetes Res 2011: 754132, 2011. 